\title{
Study on Cultivation of Interpreters' Cross-cultural Awareness
}

\author{
Mingzhu Xu \\ Chinese People's Armed Police Forces Academy \\ Langfang, China 065000
}

\begin{abstract}
Interpretation is a cross-cultural communicative activity involving high-quality understanding, analysis and processing of language information. This paper introduces the definitions of cross-cultural awareness and interpreting, and analyses the relationship between them, discussing the strategies of cultivating cross-cultural awareness in interpreting training.
\end{abstract}

Keywords-cross-culture awareness; interpretation; interpreter

\section{THE DEFINITION OF INTERPRETING AND CROSS- CULTURAL AWARENESS}

Interpretation or interpreting is the facilitating of oral or sign-language communication, either simultaneously or consecutively, between users of different language. Practically, interpreting is an activity of language shifting, but essentially, interpreting is a cross-cultural communicative activity. Cross-cultural awareness, as the cognitive aspect of cross-cultural communication, refers to the recognition of cultural conventions that can affect the thinking mode and behavior of the people ${ }^{1}$. Since interpreters are the media for cross-cultural communication, it is essential for them to find the features of other cultures which will help them to explain others' behaviors in cross-cultural communication. Cross-cultural awareness is a key factor in interpreting which can be helpful for realizing the cultural differences and find some methods to cope with the differences, because information transmission not only includes word-for-word conversions, but also the different cultural backgrounds and customs. Meanwhile, having crosscultural awareness can not only help interpreters to recognize, understand and shift from one cultural mode to another, but also create a harmonious atmosphere and make interpreting smooth and successful. Therefore, interpreters should have cross-cultural awareness.

\section{RELATIONS BETWEEN CROSS-CULTURAL AWARENESS AND INTERPRETING}

Oral expressions are different in different cultural backgrounds. An interpreter must choose proper words to express the intention of the speakers. It is necessary to sum up some cross-cultural phenomenon to train this ability. To

${ }^{1}$ Chen, G.M. and W.J.Starosta. Intercultural Communication. Belmont, CA: Wadsworth Publishing Company, 2000. know about the two languages, one must understand the cultures behind them, not just the literal meaning. Interpreting is cross-linguistic, cross-cultural and cross-social communicative activity. An interpreter should not only master language skills and language knowledge, but also have cross-cultural awareness which is an intuition for an interpreter, and it is formed by daily learning cultural background knowledge. It can help an interpreter to express the real meaning of what the speaker says. For instance, Americans are confident and frank, so when we communicate with foreigners, some ambiguous words should be avoided, such as "may, perhaps, maybe" etc. Englishmen are called gentlemen, so we'd better use polite form to interpret.

There are several components in interpreting. They are source language, encoding, memory, decoding, and target language. Source language comes from the speakers who express their meanings. Encoding is a process that the sender puts the message into a signal. Message means a serious of verbal and nonverbal symbols after encoding. Decoding is the process an interpreter organizes his words and tries to output them. Target language is what interpreters say to the listeners. Among these ingredients, encoding and decoding are the most important part. After receiving the message, an interpreter will encode a message into a signal and then decode the signal at the receiving end. Encoding is a process to encode one's ideas, emotions and conceptions into language codes, verbal and nonverbal behaviors and written symbols, while decoding is a process to interpret the meaning of information or message and symbols to the outside world. The problems of cross-cultural obstacles may occur in decoding. If interpreters don't have the crosscultural awareness, it will be hard for him to decode the message. Then the following parts will also be failures. In interpreting training, it is recognized that cross-cultural awareness is an important part which can help us to know the differences and similarities of different cultures. So this thesis will focus on how to cultivate cross-cultural awareness, in order to avoid cultural barriers and make the interpreting smooth and successful.

\section{CULTURAL DIFFERENCES IN INTERPRETATION}

As we know, oral interpreting is an extremely complicated and difficult performance. We notice it concerns two different cultures and involves participants from 
different cultural backgrounds. These differences are the major cause for the formation of cross-communicative barriers. Difficulties arising out of differences of culture constitute the most serious problems for interpreters and have produced the most far-reaching misunderstandings among listeners.

\section{A. Mode of Thinking}

Due to different cultural orientations, it is natural for having distinct modes of thinking to people in diverse nations. Language as an essential part of culture conveys people's mind and reflects different cultural connotations. Thus cross- cultural communication is usually restricted by patterns of thinking. Some scholars believe that people in eastern countries are more implicit and moral but in western countries are totally different. The westerner's thinking pattern come from postulation, with an emphasis on analysis through "linear" logic by syllogism and dialectic processes. They are prone to making very explicit statements and have little capacity with nonverbal forms of expression. In contrast, easterners tent to be intuitive, with an emphasis on synthesis through "spiral" logic and contemplation of the self and universe.

For example, Premier Zhu Rongji's press conference in the year of 2000 “你讲的这个例子很风趣, 但是跟我讲的风 马牛。” Interpreter "I think you have made a very vivid and interesting example of the estranged wife when posing your question, but I think it is dramatically different from the main point that I was taking about on Taiwan. So it is as different as earth is with heaven. (“记者会实录” 10 Sep.2000) ${ }^{2}$

Premier Zhu used a Chinese idiom in this sentence and intentionally omitted three key words “不相及” to strength the meaning of totally irrelativeness. In high-context cultures, such information is available in the concrete environment that is unnecessary to state verbally what is obvious. The obscure and indirect expression of Chinese easily made English listeners puzzled and unclear due to different thinking pattern. So the interpreter translate “风马牛” into "dramatically different" which could deliver the authentic meaning of Premier Zhu.

\section{B. Value Orientation}

As people acquiring communicative competence during the process of socialization, they gradually form their own value system. Value orientation is the core of cross-cultural communication. In some sense, the differences in value orientation are the root of most cross-cultural barriers. People from different cultures behave differently according to their own value system which could decide how a person communicates with others within his culture as well as across his culture. Obviously eastern and western worlds have decided how a person communicates with others within his culture as well as across his culture. Obviously eastern and western worlds have different values.

\footnotetext{
2 “记者会实录” 2002-09-10.

《http://www.fmprc.gov.cn/chn/xwfw/fyrth/1032/default.htm》
}

The independence, individualism, and privacy, for example, are greatly respected and valued by people in English speaking countries. They put special emphasis on individual elements, self-fulfilling and self-help. The "I" consciousness prevails: competition rather than cooperation is encouraged; personal goals take precedence over group goals; and every individual has the right to his or her private property, thoughts, and opinions. This kind of culture stresses individual initiative and achievement. As for Chinese, they respect cooperation, loyalty, and collectivism. Collectivism is characterized by a rigid social framework that distinguished between in-groups and out-groups. Collectivism means: (1). the views, needs, and goals of the in-groups rather than oneself; (2). social norms and duty defined by the in-group rather than individual to get pleasure (3). beliefs shared with the in-group rather than distinguished self from in-group. In collective societies, the "we" consciousness prevails and the individual is emotionally dependent on groups. Chinese tend to celebrate collectivism so we could gain the reason why speeches made by Chinese usually start with “尊敬的各位领导, 各位来宾, 女士们, 先 生们, 大家好! ”. But English speakers frequently give their speech with beginning of "Mr. President; Mr Chairman; Mr. Prime Minister, etc". At the great time interpreters must consider the value orientation of listeners to find an appropriate counterpart to achieve effective communication.

\section{Ethnocentrism in Cross-cultural Communication}

The ethnocentrism, which the preferred communicative style is natural and normal, predisposes people to evaluate other styles negatively. Such evaluation is likely to elicit a defensive reaction, and to form a mutual negative valuation that stems from blindness toward differences among cultures Ethnocentrism is identified by many scholars as one of the main reasons for miscommunication between or among the people of diverse cultural backgrounds. They want people to believe as they believe, to look at the world as they do, to know things as they want others to know. Our culture is a major factor in perceptual discrepancies. Culture helps supply us with our perspective of reality. We evaluate everything by our own cultural standards. The danger of such evaluation is that they are often false, misleading, and arbitrary. For instance, Americans may evaluate Japanese indirectness communication style as "ambiguous", while American directness may be received by Japanese as "immature". When communicators engage in mutual negative evaluation, the recriminatory interaction may be enough to block communication. The main factor is a lack of awareness of specific cultural differences in communication style.

\section{Cultivating CROSS-CUlture AWARENESS IN INTERPRETING}

As we know there are lots of differences between different cultures which lead to difficulties and problems in cross-cultural communications. An interpreter, who is the bridge in cross-cultural communications, should have crosscultural awareness which not only saves time in interpreting, but also avoids misunderstandings. 


\section{A. Accumulating cultural knowledge of SL and TL}

The reason for lacking cross-cultural communication ability is that we do not have enough cross-cultural knowledge, thus accumulating lots of knowledge about the two cultures is very important. An interpreter must know about customs, traditions, values, beliefs, idioms, classics, social habits, scientific technologies both in native culture and other culture. With enough knowledge, we can compare the two cultures, understand the differences between the two cultures and avoid ethnocentrism.

An interpreter has to prepare cultural knowledge for his career life, which may help him to overcome cultural barriers in interpreting. In order to accumulate the knowledge, an interpreter can benefit from foreign cultures by watching mass media like TV, internet news, CCTV news, English films, videos and newspapers, magazines and journals is also an effective way to become familiar with foreign cultures. With the progress of the IT industry and technology and further reform and opening -up of China, we can enjoy the famous films, television programs, videos and plays, famous speeches, lectures and open classes of famous universities, which can enlarge our knowledge field and advance with the time, we will gain the knowledge of medical science, law, philosophy, psychological, science and technology, education and health, etc. Meanwhile, we can observe the cultural differences in greeting, address, farewell, compliments, apology, debating and showing empathy, this a vivid channel for us to get knowledge about cultures and know what happens today in the world.

Nida states linguistic comparison between source language and target language is superficial, the difficult part in interpreting is cultural differences which may cause misunderstanding. The culture conflicts and barriers are caused by cultural differences. So if we compare the two cultures frequently, we are more likely to have a shared system which can help us to overcome cultural barriers and have a general idea of customs, traditions, habits, beliefs and people's thinking mode. One's native culture is the basis of learning other cultures. China has a tremendous rich culture and a long history. There are lots of literature works through the history, knowing about our native culture is easy for us to compare the two cultures and improve our cross-cultural awareness.

\section{B. Adequate Interpreting Practice}

Interpretation practice can strengthen communicative competence. Interpreters must not only possess cross-cultural awareness, but also cross-cultural communicative ability, and have the sensibility and judgment between the cultural differences of source language and target language, as well as speakers and listeners. And what is the most important for them is to think from the point of the speakers. One of the important ways to feel the other culture is through a great deal of interpretation practice. When negotiating, interpreters had better fully understand the cultural differences between the parties and try to avoid misunderstandings and contradictions caused by cross-cultural conflict. After practice, they can accumulate the experience and develop good habits of interpretation.
Harris and Moran point out that an interpreter should immerse himself in foreign culture. Seize every chance to join in the artistic and community activities, the carnivals, the rites, the international and fraternal or professional organizations. So it is also good for an interpreter to communicate with foreigners who are from foreign cultures. It's necessary to acquire first-hand, vivid cultural information. Communication with foreigners in a relaxing and comfortable situation is a good way for us to learn crosscultural awareness from foreigners, and it is easier for us to get more information, then we may avoid cultural barriers in interpreting successfully.

\section{Cross-cultural Empathy}

Empathy is an ability to see others from their point of views which will help us to be familiar with others and adjust ourselves to a new environment. In interpreting, we should have awareness to understand another person's thought, feelings and experiences. Samover pointed out "to be successful as an intercultural communicator, you must develop empathy, and that can be cultivated only if you become sensitive to the values and customs of the culture with which you are interacting". 3 (Samover, 2000: 261) Empathy can help us to avoid misunderstanding and conflicts.

In order to have this potential ability, the best and effective way is to have contact with different cultural environment. On the basis of understanding foreign cultures, we observe and analyze questions from the other's cultural background, which is called "empathy". This is the highest level of cross-cultural awareness. According to Hanvey, the fourth level of effective cross-cultural communication is to feel another culture as if you were an insider. So as an interpreter, first, he should have respect for the differences between native culture and foreign culture, overcome ethnical-center consciousness, get rid of wrong views and biased attitude toward gender, nation and culture. Second, because "empathy" has the characteristic of instant, it will be changed according to time and places. An interpreter should pay attention to communication scene, verbal and non-verbal behavior in cross-cultural communication and understand their natural emotions. Besides, an interpreter should improve their sensitivities to cultural values, customs and thinking mode of foreign cultures, instead of using your culture background to explain and judge the verbal and nonverbal behavior of the people from another culture, but to conjecture and use the foreign language in an idiomatic way, psychology and the behavior patterns. Moreover, it is also very necessary for an interpreter to know about the communicative purpose and demand of both parties, in this case, when we observe and analyze a problem from the perspective of the other side; we may realize the real "empathy".

\footnotetext{
${ }^{3}$ Samovar, L.A. and R.E. Porter.(eds) Intercultural communication: A Reader. Belmont, CA: Wadsworth Publishing Company, 1991.
} 


\section{CONCLUSION}

With the development of China, communication with foreign countries is growing. Therefore, there is a big demand for interpreters, and the research in this field is growing. There are many factors affecting the quality of interpreting, among which cross-cultural awareness is the basic quality an interpreter should have. Interpreting not only transmits the language itself, but also the culture. An interpreter should have strong cross-cultural awareness. Only with cross-cultural awareness, misunderstandings can be avoided, and interpreting standard can be grasped.

\section{REFERENCES}

[1] Nida, E.A . Translating Meaning. San Dimas, CA: English Language Institute, 1982.

[2] Samovar, L.A. and R.E. Porter.(eds) Intercultural communication: A Reader. Belmont, CA: Wadsworth Publishing Company, 1991.

[3] Hanvey.R. Cross-cultural Awareness, in E.C.Smith and L.F. Toward Internationalism: Readings in Cross-cultural Communication. Newbury House, 1979.

[4] Chen, G.M. and W.J.Starosta. Intercultural Communication. Belmont, CA: Wadsworth Publishing Company, 2000.

[5] Tomalin, B. and S.Stempleski. Cultural Awareness. Oxford: Oxford University Press, 1993. 